\title{
Akıllı Kentin Bir Bileşeni Olarak Akılı Ulaşım Uygulamalarının İncelenmesi: Kocaeli Büyükşehir Belediyesi Örneği
}

\section{The Analysis of Smart Transportation Implementations as a Component of Smart City: The Case of Kocaeli Metropolitan Municipality}

\author{
Ramazan Şengül, ${ }^{\mathrm{a}}$ Hande Yüksel Altıntaş ${ }^{\mathrm{b}}$ \\ a Prof. Dr., Kocaeli Üniversitesi, Kocaeli, Türkiye. \\ ramazan.sengul@kocaeli.edu.tr \\ ORCID: 0000-0002-3164-9676 \\ b Arş. Gör., Kocaeli Üniversitesi, Kocaeli, Türkiye. \\ hande.yuksel@kocaeli.edu.tr
}

ORCID: 0000-0002-7708-3911

\section{MAKALE BÍLGISİ}

\section{Makale Geçmiși:}

Başvuru tarihi: 08.04.2020

Düzeltme tarihi: 30.11 .2020

Kabul tarihi: 21.12.2020

Anahtar Kelimeler:

Akıllı Kent

Akıllı Ulaşım Sistemleri

Bilgi ve İletișim Teknolojileri
$\ddot{\mathbf{O Z}}$

Kente daha etkin ve sürdürülebilir bir yönetim anlayışının kazandırılması amacıyla Bilgi ve İletişim Teknolojilerinin (BİT) etkin bir biçimde kullanılmasını öngören akıllı kent kavramı 2000'li yılların başında gündeme gelmiştir. Akıllı ekonomi, akıllı yönetişim, akıllı çevre, akıllı yaşam, akıllı ulaşım (hareketlilik) ve akıllı insan (vatandaş) gibi bileşenlerin birbiriyle bağlantılı bir biçimde oluşturduğu bu yaklaşımda amaç kent sakinlerinin yaşam kalitesinin artırılması ve kentlerin sürdürülebilirliğinin sağlanmasıdır. Kentlerin geleceğine yön verilmesinde ekolojik duyarlılıkların rol oynaması ve gelişen yeni teknolojilerin bu amaçla kentsel yönetime uygulanması önem taşımaktadır. $\mathrm{Bu}$ bağlamda teknolojik gelişmelerden yararlanılarak ulaşımda güvenliğin sağlanması, enerji verimliliğin artırılması ve çevreye verilen zararların azaltılması gibi kazanımların elde edilmesinde önemli rol oynayan akıllı ulaşım sistemleri uygulamaları akıllı kent kavramının önemli bir bileşeni olarak öne çıkmaktadır. Dünyadaki uygulamalara paralel bir biçimde akıllı ulaşım kavramının Türkiye'de de çeşitli politika belgelerinde ve yerel yönetim uygulamalarında yerini aldığı görülmektedir. $\mathrm{Bu}$ çalışmanın amacı akıllı ulaşım sistemlerinin akıllı kent politikalarını nasıl etkilediğini ortaya koymaktır. Çalışmada vaka analizi yapılmıştır. Sanayi kenti olan ve çeşitli kentsel sorunlara muhatap olan Kocaeli'nde akıllı kent politikaları kapsamında büyükşehir belediyesi tarafından uygulanan akıllı ulaşım politikaları ele alınmıştır. Akıllı ulaşım sistemlerin etkisini tespit etmeye yönelik olarak ulusal ve yerel yönetim düzeyinde konuyla ilgili olarak üretilen belgeler incelenmiş ve ayrıca Kocaeli Büyükşehir Belediyesi'ndeki yetkililerle mülakatlar gerçekleştirilmiştir.

\section{ABSTRACT}

The term of smart city, which envisages the effective use of Information and Communication Technologies (ICT) in order to give to the city a more effective and sustainable management approach, has emerged in the early 2000s. In the smart city concept which is formed by the components such as smart economy, smart governance, smart environment, smart life, smart transportation (mobility) and smart people (citizen), the aim is to increase the quality of life of the citizens and to ensure the sustainability of the cities. It is important that shaping the future of cities with ecological sensibilities and the application of new technologies to urban management for this purpose. In this context, smart transportation systems, which play an important role in obtaining gains such as ensuring transportation safety, increasing energy efficiency and decreasing damages to environment by making use of technological developments, stand out as an important component of the concept of the smart city. In Turkey, it is observed that the term of smart transportation systems takes place in the scope of the several policy documents and local government practices, correspondingly with the world. The aim of this study is to determine how smart transportation systems affect smart city policies. Case study method was used in the study. Smart transportation policies implemented by the metropolitan municipality are discussed within the scope of smart city policies in Kocaeli, which is an industrial city and has various urban problems. In order to determine the impact of smart transportation systems, the documents produced on the subject at the national and local government level were examined and interviews were conducted with the officials in the Kocaeli Metropolitan Municipality. 


\section{Atıf Bilgisi / Reference Information}

Şengül, R. ve Yüksel Altıntaş, H. (2020). Akıllı Kentin Bir Bileşeni Olarak Akıllı Ulaşım Uygulamalarının İncelenmesi: Kocaeli Büyükşehir Belediyesi Örneği. Uluslararası Kültürel ve Sosyal Araştırmalar Dergisi (UKSAD), 6 (2), Kış, s. 487-502.

\section{Giriş}

Hızlı nüfus artışı ve kentleşme hareketlerine koşut olarak ortaya çıkan enerji, barınma ve ulaşım gibi ihtiyaçların karşılanması giderek zorlaşmakta ve çevresel değerler üzerinde daha fazla bask1 yaratmaktadır. Dünya nüfusunun büyük bir kısmını barındıran, mal ve hizmet akışını sağlayan kentlerde bu sorunlar daha görünür hale gelmiştir. Gelecek kuşakların sağ lıklı bir kent ortamında yaşama hakkının korunması her ne kadar tüm insanlığı kapsayan ortak bir çabayı gerektirse de kent yönetimleri karar alıcı ve uygulayıcılar olarak bu hedefe ulaşılmasında önemli bir role sahiptir.

Kentsel mekanda yaşanan sorunların bertaraf edilmesinde teknolojik gelişmelerden yararlanılması kaçınılmazdır. Günümüzde kentlerin yalnızca bütünleşik ve yeşil alana sahip olması yeterli olmayıp, aynı zamanda "akıllı" olması gereklidir (Ercoşkun ve Karaaslan, 2009: 28). Akıllı kent politikaları, dünyada birçok yerel yönetimin vizyon belgelerinde yer almakla kalmayıp uygulama safhasına geçirilmiştir. Bilgi ve İletişim Teknolojilerinin (BİT) kent yönetimi alanında etkin bir biçimde kullanılmasını öngören akıllı kent kavramı 2000'li yılların başında akademik alanda yapılan çalışmalarla birlikte gündeme gelmiştir.

Bir kentin "akıllı" sıfatını kazanabilmesi ulaşımdan ekonomiye, çevreden yönetişime çeşitli bileşenlerin bilgi ve iletişim teknolojilerindeki gelişmelerden yararlanılarak doğayla uyumlu sürdürülebilir bir sistem oluşturmasıyla mümkün olmaktadır. Bu noktada kent yönetiminin en sorunlu alanlarından biri olan ulaşım boyutunun akıllı kent yaklaşımıyla ele alınması artık bir seçenek değil zorunluluk halini almıştır. Akıllı ulaşım sistemleri, bilgi ve iletişim alanındaki teknolojik yenilikleri ulaşım ağıyla birleştirerek vatandaşların yaşamını kolaylaştırmaya odaklanmıştır. Kentlerde yaşayanlar için zaman yönetiminin oldukça önemli bir husus olduğu göz önüne alındığında kent içi yer değiştirmelerin uygun zaman ve koşullarda gerçekleşmesinin zaman ve iş kaybını önlemeye yönelik faydası daha iyi anlaşılmaktadır. Teknolojik yeniliklerin kentin ulaşım tekniklerine uyarlanması ile hizmet kullanıcılarına kaliteli ulaşım hizmeti sağlanmış olacak ve kentsel yaşam konforunda artış gerçekleşecektir.

Dünyadaki uygulamalara paralel bir biçimde akıllı ulaşım yaklaşım ve politikalarının Türkiye'de de çeşitli politika belgelerinde ve yerel yönetim uygulamalarında yerini aldığ 1 görülmektedir. Çalışmada akıllı ulaşım sistemlerin akıllı kent politikalarına etkisi Kocaeli Büyükşehir Belediyesi örneği üzerinden ele alınmıştır. Bu bağlamda öncelikle akıllı kent ve bileşenleri açıklanmış, izleyen bölümde akıllı ulaşım kavramına yer verilerek dünyadaki ve Türkiye'deki yansımaları incelenmiştir. Son bölümde ise Kocaeli Büyükşehir Belediyesi’nin akıllı ulaşım sistemi analiz edilmiştir.

\section{Akıllı Kent ve Bileşenleri}

Giderek baş edilmesi güç bir hal alan kentleşme sorunları ve artan çevresel krizlerin yarattığ 1 baskı hem uluslararası alanda hem de yerel düzeyde kent yönetimlerini çeşitli önlemler almaya ve yeni çözüm arayışları bulmaya itmiştir. 1990'lı yılların başında yeni kentleşme hareketi ile başlayan bu süreçte farklı yaklaşımlar ortaya çıkmıştır. Sürdürülebilir kentler, ekolojik kentler, akıllı büyüme, yavaş kentler, düşük karbon kentler, yaşanabilir kentler, dijital kentler ve akıllı kentler bu yaklaşımlar çerçevesinde gelişmiş kavramlar olarak aynı temelden hareketle planlama ve tasarım önerileri sunmaktadır (Sınmaz, 2013: 77).

Akıllı kent kavramıyla ilgili literatür incelendiğinde net bir tanımın bulunmadığı görülmektedir. Hall (2000: 1) akıllı kentleri; yollar, köprüler, tüneller, raylar/metrolar, havalimanları, deniz limanları, iletişim, su, güç ve hatta büyük binalar da dahil olmak üzere kritik öneme sahip tüm altyapılarının durumlarını izleyen ve bütünleştiren, kaynaklarını daha iyi optimize eden, önleyici bakım planını yapabilen ve güvenliği sağlayabilen kentler olarak tanımlamaktadır. 
Bir diğer tanımda ise akıllı kentin; ekonomi, insan, yönetişim, ulaşım, çevre ve yaşam alanlarında ileriye dönük bir şekilde iyi performans gösteren, kendinden emin, özgür ve bilinçli vatandaşların yetenek ve faaliyetlerinin akıllı kombinasyonu üzerine kurulmuş bir kent olduğu vurgulanmaktadır (Giffinger vd. 2007: 11).

Dameri (2013: 2549), yönetimi ve gelişimi için gerekli politikaları belirleme gücüne sahip, iyi tanımlanmış hedeflerle yönetilen ve sınırları belirli olan coğrafi bir alan olarak tanımladığı akıllı kentlerin aynı zamanda katılım, çevre kalitesi, akıllı gelişme konularında vatandaşların refahının sağlanması için işbirliğine açık ve bilgi iletişim teknolojisi, lojistik, enerji üretimi gibi alanlarda yüksek teknolojiye sahip olduğunu belirtmektedir.

Avrupa Birliği akıllı kentleri, geleneksel hizmetlerin ve ağların sayısal ve telekomünikasyon teknolojileri kullanarak, yaşayanların ve işyerlerinin fayda sağlayacağı biçimde daha verimli hale getirildiği yerler olarak tanımlamaktadır (Türkiye Bilişim Vakfı, 2016: 9). Akıllı kent, Bilgi ve İletişim Teknolojilerinin (BİT) konuşma özgürlüğünü, kamuya açık bilgilere ve servislere erişilebilirliği güçlendirdiği kenttir (Partridge, 2004).

Türkiye'de akıllı kent kavramı ve bileşenleri ile ilgili politika ve eylemlerin kapsamlı olarak belirlendiği ilk üst düzey politika belgesi Onuncu Kalkınma Planı'dır. Akıllı kent uygulamalarının sağlık, ulaşım, afet yönetimi gibi alanlarda yaygınlaştırılması ve akıllı kentlere dönüşümün gerçekleştirilmesi için gerekli desteklerin sağlanması hedeflenmiştir (Kalkınma Bakanlığı, 2013). Onuncu Kalkınma Planı'nın etkisi ile pek çok sektörel ve tematik strateji ile kurum stratejik planında da akıllı kent ve bileşenlerine ilişkin politikalara yer verilmiştir (Çevre ve Şehircilik Bakanlığ $1,2019: 29)^{1}$.

Akıllı kent alanına ilişkin gelişmelerin 2019 yılında ivme kazandığı görülmektedir. Çevre ve Şehircilik Bakanlığı tarafından hazırlanan "2019-2022 Ulusal Akıllı Şehirler Stratejisi ve Eylem Planı" ile ulusal ölçekte bir yol haritası belirlenmiştir. Aynı yıl hazırlanan On Birinci Kalkınma Planı'nda ise bu belge temel alınarak hedefler ve politikalar oluşturulmuştur. Yerel yönetimlerin akıllı kent olma yolunda oluşturacakları strateji ve planların teşvik edileceği belirtilmiştir (Çevre ve Şehircilik Bakanlığı, 2019: 29; Strateji ve Bütçe Başkanlığı, 2019: 174).

Akıllı kentlerle ilgili literatür incelendiğinde, çevresel sürdürülebilirlik, yaşam kalitesi ve refah, katılım, enformasyon ve entelektüel sermaye olmak üzere dört temel hedef grubu belirlenebilmektedir (Dameri, 2013: 2549). Bu kavramlardan hareketle kapsamlı bir tanım yapılacak olursa akıllı kentler; fiziksel altyapıları gelişmiş, ulaşım olanaklarıyla hareketliliği ve kolay erişimi sağlayan, enerjiyi muhafaza eden, su ve hava kalitesini arttıran, hızlı bir biçimde sorunları tanımlama ve çözme yetisine sahip, doğal afetlere karşı tedbirli, kolay karar almak ve kaynakları etkin kullanabilmek için veri toplayan ve tüm paydaşlarıyla bilgi paylaşan bütünleşik bir sistem ağından oluşmaktadır (Moss ve Litow, 2009: 2). Akıllı toplum, akıllı ekonomi, akıllı çevre, akıllı yönetim, akıllı yaşam, akıllı ulaşım, akıllı teknolojiler ve akıllı şebekeler gibi unsurların birbiriyle bağlantılı bir biçimde oluşturduğu bu sistemde amaç kent sakinlerinin yaşam kalitesinin arttırılması ve kentlerin sürdürülebilirliğinin sağlanmasıdır.

\footnotetext{
${ }^{1} 2015$-2018 Bilgi Toplumu Stratejisi ve Eylem Planı, 2016-2019 Ulusal e-Devlet Stratejisi ve Eylem Planı, 2010-2023 KENTGES Bütünleşik Kentsel Gelişme Stratejisi ve Eylem Planı, 2016- 2019 Ulusal Siber Güvenlik Stratejisi ve Eylem Planı, 2017-2023 Ulusal Enerji Verimliliği Eylem Planı,

2014-2023 Ulusal Akıllı Ulaşım Sistemleri Strateji Belgesi ve Eki Eylem Planı.
} 
Tablo 1:Ak1llı Bir Kentin Özellikleri ve Ögeleri

\begin{tabular}{|c|c|}
\hline $\begin{array}{l}\text { Akıllı Ekonomi } \\
\text { (Rekabet Edebilirlik) }\end{array}$ & $\begin{array}{l}\text { Akıllı İnsan } \\
\text { (Sosyal ve Beşeri Sermaye) }\end{array}$ \\
\hline $\begin{array}{l}\text { Yenilikçi Ruh } \\
\text { Girişimcilik } \\
\text { Ekonomik İmaj\& Ticari Markalar } \\
\text { Üretkenlik } \\
\text { Piyasa Esnekliği } \\
\text { Uluslararası İlişkiler } \\
\text { Dönüşüm Kabiliyeti }\end{array}$ & $\begin{array}{l}\text { Yeterlilik Düzeyi } \\
\text { Yaşam Boyu Öğrenmeye Yatkınlık } \\
\text { Sosyal ve Etnik Çoğulculuk } \\
\text { Esneklik } \\
\text { Yaratıcılık } \\
\text { Kozmopolitlik/ Açık Fikirlilik } \\
\text { Kamusal Hayata Katılım }\end{array}$ \\
\hline $\begin{array}{l}\text { Akıllı Yönetişim } \\
\text { (Katılım) }\end{array}$ & $\begin{array}{l}\text { Akıllı Hareketlilik } \\
\text { (Ulaşım ve BITT) }\end{array}$ \\
\hline $\begin{array}{l}\text { Karar Alma Sürecine Katılım } \\
\text { Kamusal ve Sosyal Hizmetler } \\
\text { Şeffaf Yönetim } \\
\text { Politik Stratejiler\& Öngörüler }\end{array}$ & $\begin{array}{l}\text { Yerel Ulaşılabilirlik } \\
\text { Ulusal/ Uluslararası Ulaşılabilirlik } \\
\text { BITT Altyapısının Varlığı } \\
\text { Sürdürülebilir, Yenilikçi ve Güvenli Ulaşım Sistemleri }\end{array}$ \\
\hline $\begin{array}{l}\text { Akıllı Çevre } \\
\text { (Doğal Kaynaklar) }\end{array}$ & $\begin{array}{l}\text { Akıllı Yaşam } \\
\text { (Yaşam Kalitesi) }\end{array}$ \\
\hline $\begin{array}{l}\text { Doğa Koşullarının Çekiciliği } \\
\text { Kirlilik } \\
\text { Çevresel Koruma } \\
\text { Sürdürülebilir Kaynak Yönetimi }\end{array}$ & $\begin{array}{l}\text { Kültürel Olanaklar } \\
\text { Sağllk Şartları } \\
\text { Bireysel Güvenlik } \\
\text { Konut Kalitesi } \\
\text { Eğitim Olanakları } \\
\text { Turistik Çekicilik }\end{array}$ \\
\hline
\end{tabular}

Kaynak: Giffinger, (2007: 12)

Yerel yönetimler, bilgi ve iletişim teknolojilerinin sağladığı imkanlardan istifade ederek yerel kamu hizmet politikalarını yeniden şekillendirmektedir. Dünyanın birçok ülkesinde uygulamaya konulan akıllı kent politikalarıyla kentsel yaşamın ihtiyaç ve beklentilerinin daha hızlı, etkili ve kaliteli şekilde karşılanmasına çalışılmaktadır. Ayrıca akıllı kent yaklaşımını esas alan politikalarla bir yandan yerel kalkınmanın hızlanmasını hedeflenirken diğer yandan yerel demokrasinin güçlenmesine sağlayacağ katkılardan yararlanılması düşünülmektedir. Yerel yönetimler bu süreçte kendi imkanlarını kullanmanın yanı sıra merkezi yönetimden veya ulusüstü kurumlardan finansman desteği sağlamaktadırlar (Şengül, 2017: 455). Akıllı kent politikaları çerçevesinde yerel yönetimler kentte yaşayanların yaşam kalitesinin yükseltilmesine yönelik girişimlerinde ulaşım faktörü önemli bir yer tutmaktadır. Ulaşım hizmetlerinin optimal şekilde sunulması ve kullanıcı memnuniyetinin sağlanması ile toplumsal beklentiler karşılanmış olacaktır.

\section{Dünyada Akıllı Ulaşım Sistemlerinin Gelişimi ve Uygulamalar}

Dünya nüfusunun yarısından fazlasının kentlerde yaşadığı bilinmektedir. 2050 yılına doğru ise kentlerde yaşayan nüfus oranının \%66'ya çıkacağı tahmin edilmektedir (www.unfpa.org, 15.11.2016). Nüfus artış1 ve buna bağlı olarak gelişen plansız kentleşmenin neden olduğu en büyük sorunlardan biri ulaşımdır. Bu tahminler ışığında, hem gelecekte meydana gelebilecek sorunlara karşı önlemlerin alınması hem de mevcut durumda kentlerde yoğunlaşmış olan ulaşım sorunlarının çözümü için Akıllı Ulaşım Sistemlerinden (AUS) yararlanıldığı görülmektedir.

Akıllı Ulaşım Sistemleri, seyahat sürelerinin azaltılması, trafik güvenliğinin sağlanması, mevcut yol kapasitelerinin en uygun biçimde kullanılması, hareketliliğin artırılması, enerji verimliliği elde edilerek ülke ekonomisine katkı sağlanması ve çevreye verilen zararın en aza indirilmesi gibi hedefler doğrultusunda geliştirilen kullanıcı-araç-altyapı-merkez arasında çok yönlü veri alışverişi ile izleme, 
ölçme, analiz ve kontrol süreçlerini kapsayan sistemlerdir (Tektaş vd., 2016: 561). Akıllı Ulaşım Sistemlerinin, altyap1 yatırımlarının optimizasyonunu sağladığı tespit edilmiştir. Mevcut altyap1 sistemlerinin etkin hale gelmesine yardımcı olması nedeniyle yeni altyapı yatırımlarına olan gereksinimi ortadan kaldırmakta veya azaltmaktadır (MTES/MCT, 2017: 7).

Akıllı Ulaşım Sistemleri, gelişmiş bilgi ve iletişim sistemlerini kullanmaktadır. Günlük ulaşım yönetimini düzenleyen bu sistemler çevre duyarlılığını dikkate alarak ulaşımın etkinlik ve güvenliğini temin etmektedir. Akıllı Ulaşım Sistemleri, akıllı kentlerin bir bileşeni olarak büyük kentlerin yönetimini kolaylaştırmaktadır (MTES/MCT, 2017: 3).

Avrupa Birliği’nin 7 Temmuz 2010 tarihli Direktifinin 4.maddesinde Akıllı Ulaşım Sistemi “Altyap1, araçlar, kullanıcıları içine alan yol ulaşımı alanında ve sirkülasyon ve hareket yönetiminde ve diğer ulaşım araçlar içinde bilgi ve iletişim teknolojilerinin uygulandığ 1 sistemdir” şeklinde tanımlanmıştır. Bu direktifle $\mathrm{AB}$ içinde akıllı ulaşım sistemleri için bir çerçeve çizilmiştir. Direktifin 2.maddesinde;

- Yol, yer değiştirme ve sirkülasyona ilişkin verilerin optimal kullanımı

- Ak1llı Ulaşım Sistemleri hizmetlerinin devamlılı̆̆1

- Akıllı Ulaşım Sistemlerinin güvenlik ve yol güvenliğine uyarlanması

- Ulaşım altyapıları ile ulaşım araçları arasında bağ kurulması hususlarına öncelik verilmiştir (bison-fute.gouv.fr, 16.03.2018).

Genel olarak tanımlandığında Akıllı Ulaşım Sistemleri, ulaşım alanındaki sorunların çözümünde insan üzerindeki düşünme ve karar verme yükünün hafifletilmesine yönelik bir çabayı ifade etmektedir. $\mathrm{Bu}$ bağlamda trafik ışıklarının uygulamaya geçmesiyle, araç ve yaya geçişlerinin zamanının belirlenmesi, kavşaklarda hangi yöne giden aracın hangi yöne giden araca ne kadar süreyle yol vereceğinin çözümlenmesi açısından ilk Akıllı Ulaşım Sistemi uygulamasının gerçekleştiği söylenebilir. Günümüzde ise Akıllı Ulaşım Sistemi denildiğinde daha çok elektronik ve bilgisayar teknolojisi odaklı düzenleme ve yönlendirmenin hakim olduğu sistemler ön plana çıkmaktadır. Bu çerçeveden bakıldığında 1960'ların sonunda kullanıma giren elektronik değişken mesaj işaretleri ve kırmızı 1şık kameraları ilk Akıllı Ulaşım Sistemi uygulamaları olarak değerlendirilmektedir (Ulaştırma, Denizcilik ve Haberleşme Bakanlığı, 2014: 12).

Birinci aşama olarak adlandırılabilecek ve 1960 ve 1970’li yılları kapsayan dönemde ilk AUS araştırmalarına başlanmıştır. İlk araştırmalar Japonya, Amerika ve Almanya' da gerçekleştirilmiştir. Oluşturulan sistemlerde ortak olarak güzergah/rota kılavuzlama yöntemi üzerinde durulmuş ve büyük merkezi bilgisayarları ve iletişim sistemleri olan devasa merkezi işletim sistemlerine dayandırılmıştır. İkinci aşama ise 1980'den 1995 yılına kadar olan dönemi kapsamaktadır. Japonya'da araç rota belirleme sisteminin temelini oluşturan Yol/Otomobil İletişim Sistemi (RACS) Projesi üzerinde yapılan çalışmalar 1984 yılında başlamıştır. Esas olarak otomobil üreticileri tarafından başlatılan Daha Etkin ve Güvenli bir Avrupa Trafik Sistemi Programı (PROMETHEUS) ve Avrupa Birliği tarafından başlatılan Avrupa'da Araç Güvenliği İçin Yol Alt Yapısı (DRIVE) adlı iki proje aynı anda yürütülmüştür. Günümüzde ise üçüncü aşamaya girilmiştir. Gelinen bu son aşamada ilk olarak öne çıkan özellik, AUS'un pratik uygulamalarının görülmeye başlanmasıdır. İkinci olarak, AUS sadece otomobil trafiğinin sebep olduğu problemlerin çözümü için değil diğer türler arası problemlerin çözümü için de dikkate alınmaya başlanmıştır. Son olarak da AUS ulusal ve uluslararası genel bilgi teknolojisi hiyerarşisinde önemli bir unsur olarak tanınmaya başlanmıştır (Yardım ve Akyıldız, 2005: 406-407). 
Tablo 2: Avrupa, Amerika ve Japonya'da AUS Politika ve Planları

\begin{tabular}{|c|c|c|}
\hline Avrupa & Amerika & Japonya \\
\hline $\begin{array}{l}\text {-Karayolu trafik ve seyahat } \\
\text { verilerinin optimal kullanımı } \\
\text {-Trafik yönetimi ve yük } \\
\text { taşımacılığı yönetiminde AUS } \\
\text { hizmetlerinin devamlılığı } \\
\text {-AUS karayolu güvenliği ve } \\
\text { emniyeti uygulamaları } \\
\text {-Taşıtların ulaştırma altyapısına } \\
\text { bağlantısının sağlanması }\end{array}$ & $\begin{array}{l}\text {-AUS teknolojilerinin } \\
\text { yaygınlaştırılması ile ilgili } \\
\text { yöntemlerin kullanılması } \\
\text {-Trafik operasyonları } \\
\text {-Acil durum ve kaza yönetimi } \\
\text {-Yüzey ulaşım şebekesi } \\
\text { yönetimi } \\
\text {-Yük yönetimi } \\
\text {-Trafik akış bilgisi ve trafik } \\
\text { sıkışıklığı yönetimi }\end{array}$ & $\begin{array}{l}\text {-Akıllı yol kullanımı } \\
\text {-Sürücü ve yayaların güvenliği } \\
\text {-Verimli ve konforlu ulaşımın } \\
\text { sağlanması } \\
\text {-Trafik kazaları, trafik sıkışıklığı, } \\
\text { çevresel etkiler ve enerji tüketimi }\end{array}$ \\
\hline
\end{tabular}

Kaynak: Tektaş vd., 2016: 563 ve 564'den tablolaştırılmıştır.

Ulaşım alanında yaşanan sorunların çözümüne önemli katkılar sağlayan AUS politika ve planları gelişen teknolojik olanaklarla birlikte her geçen gün daha kapsamlı bir hal almaktadır. Dünyanın çeşitli ülkelerinde yaygın bir biçimde kullanılan uygulamalar şu şekildedir (Xsights, 2016):

- Fransa'nın başkenti Paris'te düşük miktarda yıllık abonelik ücreti ödeyenler yine düşük miktarda saatlik ücretlerle bisiklet (Velolib) veya elektrikli otomobil (Autolib) kiralayabilmektedir. Boş araç ve otoparkların akıllı telefon uygulaması ile bulunmasına olanak sağlayan sistemin amacı, kent içinde araç kullanımını en aza indirmektir.

- Avusturya'nın başkenti Viyana'da toplu taşımacılık kartları, gerçekleştirilen ulaşımın türüne, kat edilen mesafeye ve aktarmalara göre ücreti tüketicinin yararına olacak biçimde ayrı ayrı hesaplamaktadır. Böylece bireyler toplu taşıma kullanmaya özendirilmektedir.

- Singapur dünyada araç kullanımına bağlı trafiği engellemek için sıkışıklık vergisi alan tek kent olup kameralar ve GPS cihazlarıyla trafik sıkışıklığı ölçülmekte ve buna neden olan araçlar otomatik olarak vergilendirilmektedir.

- İspanya'nın Barcelona kentinde, kent içi otobüs sistemi enerji ve zamandan tasarruf sağlamak amacıyla yeniden düzenlenmiştir. Hatlar yeniden belirlenmiş, otobüs duraklarına varış bilgi sistemi konulmuş ve aktarma bilgileri yolculara iletilmiştir. Sistem aracıllğıyla otobüsler yaklaştığında trafik ışıkları yeşile dönmekte ve böylece sefer süreleri kısalmaktadır.

- Hollanda'nın Amsterdam kentinde ise yeni otopark alanı açılmasının kısıtlanmasına katkı sağlayan "Mobypark" akıllı telefon uygulaması kullanılmaktadır. Bu uygulama aracılığıyla özel şahıslara ait boş otopark alanları ihtiyaç duyanlara kiralanmakta ve trafik rahatlamaktadır.

Kanada'nın Montreal kentinde kurulan akıllı ulaşım sisteminde trafik 1şılarına riayet edilip edilmediğini takip eden 2000 kontrolör, 500 kamera ve $10 \quad 000$ iletişim ekipmanı kullanılmaktadır (ville.montreal.qc.ca, 15.03.2018). Montreal, Kuzey Amerika'da toplu taşım araçlarının en fazla kullanıldığ 4):

- Toplu taşım araçlarına yatırımı arttırarak otomobile bağımlılığı azaltmak

- Alışkanlıkları değiştirmek ve kentsel yaşam kalitesini arttırmak

- Yayalara öncelik vermek

- Montreal'in kalkınmasında toplu taşımı temel taş yapmak

- Bisiklet ulaşımının altyapı imkanlarını geliştirmek

- Yol kazaların $\% 40$ azaltmak

- Yol paylaşımını yeniden düşünmek

- Ekonomik olan seyahat modellerini teşvik etmek

- Performansı yüksek yenilikçi teknolojiler kullanmak

- Akıllı ulaşım sistemleri üzerine bir plan kabul etmek 


\section{Türkiye'de Akılıı Ulaşım}

Türkiye'de akıllı kent kavramına ilişkin ilk politikaların akıllı ulaşım bileşenine yönelik olarak geliştirildiği görülmektedir. Ulusal Bilim ve Teknoloji Politikaları 2003-2023 Strateji Belgesi'nde; "Karayolu ulaşımı için akıllı araçlar ve akıllı yol sistemleri geliştirebilmek" ve "Ulaştırma ve turizm üst yapıları için yangın ve güvenlik sistemleri geliştirebilmek" eylemleri belirlenmiştir (Çevre ve Şehircilik Bakanlığ1, 2019: 27). İlerleyen süreçte akıllı ulaşım sistemlerinin yaygınlaştırılması hedefinin kalkınma planlarında, çeşitli politika ve strateji belgelerinde yer aldığının altını çizmek gerekir.

Onuncu Kalkınma Planı’nda “Kentiçi ulaşımda trafik yönetimi ve toplu taşıma hizmetlerinde bilgi teknolojileri ve akıllı ulaşım sistemlerinden etkin bir şekilde faydalanılacaktır" ibaresi yer almakta ve enerji verimliliğinin sağlanması için akıllı bisiklet sistemlerinin yaygınlaştırılması hedeflenmektedir (Kalkınma Bakanlığı, 2013: 131, 177). Akıllı ulaşım hedeflerinin yer aldığ1 diğer politika belgeleri şu şekilde sıralanabilir: Ulaştırma, Denizcilik ve Haberleşme Bakanlığı Stratejik Planı (2009-2013), Bilgi Toplumu Stratejisi ve Eylem Planı, Ulaşım ve İletişim Stratejisi Hedef 2023, Ulusal İklim Değişikliği ve Strateji Belgesi, Ulusal Bilim Teknoloji ve Yenilik Stratejisi ve Eylem Planı, Trafik Güvenliği Eylem Plan1, Enerji Verimliliği Strateji Belgesi (Akbaş, 2013: 272).

Farklı kamu otoritelerince hazırlanan bu belgeler incelendiğinde ulaşımda güvenliğin ve sürdürülebilirliğin sağlanması, çevreye verilen zararın azaltılması, teknolojik gelişmelerden etkin bir biçimde yararlanılması ve bu bağlamda akıllı ulaşım sistemlerinin yaygınlaşması için hedef ve eylemlerin belirlendiği görülmektedir.

Akıllı ulaşım sistemleri ile ilgili daha önce çeşitli belgelerde dağınık bir biçimde yer alan stratejik politika, hedef ve eylemlerin konuyu bir bütün olarak ele alan bir strateji belgesinde yer alması Ulusal Akıllı Ulaşım Sistemleri Strateji Belgesi (2014-2023)'nin hazırlanması ile gerçekleşmiştir. Bütün ulaşım çeşitlerinde bilgi ve iletişim teknolojilerinin kullanılmasıyla elde edilen gerçek zamanlı bilgiler aracılığıyla entegre, güvenli, etkin, verimli, yeniliğe açık, çevre dostu, sürdürülebilir ve akıllı bir ulaşım ağına sahip olmak, yolcu ve yük hareketliliğini kolaylaştırmak belgenin genel amacı olarak belirlenmiştir (Ulaştırma, Denizcilik ve Haberleşme Bakanlığı, 2014).

Akıllı ulaşım sistemlerine duyulan ihtiyaca vurgu yapan bir diğer belge ise Kalkınma Bakanlığı tarafından hazırlanan "Sürdürülebilir Kalkınma Hedefleri Kapsamında Türkiye'nin Mevcut Durum Analizi Raporu"dur. Birleşmiş Milletler (BM) Sürdürülebilir Kalkınma Zirvesi'nde Sürdürülebilir Kalkınma için 2030 Gündemi belgesi kapsamında belirlenen hedefler açısından Türkiye'nin mevcut durumunun analiz edildiği raporda yeni bir küresel eğilim olan "akıllı şehirler” kapsamında akıllı ulaşım sistemleri ile ilgili bir politika hazırlığına ihtiyaç olduğu saptanmıştır (Kalkınma Bakanlığı, 2017).

On Birinci Kalkınma Planı'nda ise “Karayolu ağında enerji ve zaman tasarrufunu, trafik güvenliğini, karayolu kapasitesinin etkin kullanımını sağlayan AUS ile ilgili mimari yerel yönetimleri de kapsayacak şekilde tamamlanarak uygulamaya konulacaktır" hedefi yer almaktadır (Kalkınma Bakanlığı, 2019: 118).

2000'li yılların başından bu yana çeşitli politika belgelerinde yer bulan akıllı ulaşım stratejisi yerel yönetimler, özel sektör ve sivil toplum kuruluşlarının girişimleriyle ivme kazanmaktadır. Çerçi (2015), 2013 yılında 40 belediye ile yapılan "Belediyeler Akıllı Kent Uygulamaları Anketi'nin sonuçlarına göre belediyelerde kentsel hizmetler ve ulaşım alanındaki akıllı kent uygulamalarının öne çıtı̆̆ını, enerji ve su alanındaki akıllı kent uygulamalarının daha az sayıda belediye tarafından hayata geçirildiğini belirtmektedir.

Akıllı ulaşım sistemleriyle ilgili girişimlerin Türkiye'deki kentlerde çeşitli düzeylerde uygulama alanı bulduğu görülmektedir. Yaman (2014), günümüzde gelinen noktada dünyada ve Türkiye'de akı1lı ulaşım sistemleri uygulamalarının öncelikle akıllı altyapı, akıllı araçlar, akıllı trafik yönetimi (akıllı kavşak yönetimi, akıllı elektronik denetleme sistemleri, vb.), akıllı ulaşım yönetimi (akıllı duraklar, akıllı toplu 
taşıma sistemleri, vb.) ve otomatik ödeme sistemleri gibi alt başlıklarda incelenmesi gerektiğine vurgu yapmaktadır.

Türkiye'de akıllı ulaşım sistemlerini merkeze alan girişimlerin öncelikle nüfusun yaklaşık olarak \%20'sini barındıran İstanbul'da uygulama alanı bulduğu görülmektedir. İstanbul dışında Konya, İzmir, Kocaeli, Eskişehir, Antalya, Ankara, Bursa, Gaziantep, Manisa gibi kentlerde de genelde kentsel hizmetler kapsamında çeşitli uygulamalar hayata geçirilmiştir. Ancak uyumluluk, entegrasyon ve birlikte çalışabilirlik konuları Türkiye için bütünlüklü bir akıllı ulaşım sistemi uygulamasının oluşmasına engel teşkil etmektedir (Akıllı Ulaşım Sistemleri Derneği, 2017: 7).

\section{1. İstanbul'da Akılı Ulaşım Uygulamaları}

Akıllı ulaşım sistemleri uygulamalarının Türkiye'de trafik yönetim ve denetiminde kullanımı ilk kez İstanbul'da İstanbul Büyükşehir Belediyesi Trafik Müdürlüğü tarafindan gerçekleştirilmiştir. İstanbul'daki akıllı ulaşım sistemi uygulamaları ise şu şekildedir (Eroğlu 2013: 157-160, isbak.istanbul, 11.04.2018):

Akyolbil: Kent içi toplu taşımada denetimin sağlanması, yolcuların bilgilendirilmesi amacıyla taşıt takip, filo yönetimi ve yolcu bilgilendirme sistemidir.

Filo Komuta Sistemi Uygulaması: Araçların bilgisayar üzerinden gerçek zamanlı olarak her zaman denetlenebilir bir şekilde yönetilmesini hedeflemektedir. Otobüslerde bulunan bilgisayarlar ile seyir bilgisi elde edilmekte olası gecikme nedenleri analiz edilip sorun oluşmadan önce çözüm geliştirilebilmektedir. Sistem kullanım ihlalini anında merkeze bildirmekte ve acil durumlarda da ilgili mercileri harekete geçirmek için otomatik mesaj gönderilmesini sağlamaktadır.

Toplu Ulaşım Bilgi Sistemi: Kullanıcıların metro, metrobüs, raylı sistemler, deniz ulaşımı, yürüme, merdiven, rampa yollar ile araçlarını tercih ederek en kısa yol, en hızlı rota ve en düşük maliyet analizlerini yapabilmesine olanak sağlayan web tabanlı bir hizmettir.

Akbil-İstanbulkart ve Elektronik Bilet: Kağıt bilet ve nakit para ile gerçekleştirilen toplu taşıma 1995'te Akbil ile değişime uğramış ve Türkiye'nin ilk elektronik bilet uygulaması gerçekleştirilmiştir. Akbil uygulamasının sürekli geliştirilmesiyle sadece toplu taşıma değil, personel takibi, otopark ve ödeme sistemlerinde kullanılmak üzere İstanbulkart hizmete sunulmuştur. Müze, kampüs, kişisel tanıtım kartı, alı̧̧veriş vb. uygulamalar şehir kartı niteliğinde olan bu uygulama ile gerçekleştirilebilmektedir.

MobIETT Uygulaması: Cep telefonu uygulamaları ile toplu taşımayı kullanan yolcuların gerçek zamanlı olarak toplu taşıma hatlarına ait durak, sefer tarifesi ve güzergah bilgilerine, otobüslerin tahmini geliş sürelerine erişilebilmekte, uygulama üzerinden anlık mesaj ile toplu taşıma hizmetlerine ilişkin talep ve şikayetler alınabilmektedir.

Trafik Kontrol Merkezi: Kentin çeşitli noktalarına farklı amaçlarla yerleştirilen trafik ölçüm, gözlem, denetim sistemleri ile tünel işletim merkezinden alınan görsel ve sayısal bilgiler teknolojik araçlarla analiz edilmekte, kentte sosyal yaşamı ve ulaşımı etkileyebilecek diğer bilgiler toplanarak kent trafiği yönetilmektedir.

\subsection{Ankara'da Akılı Ulaşım Uygulamaları}

Ankara'daki akıllı ulaşım uygulamaları şu şekilde sıralanabilir (Kesgin, Aydemir ve Dolaner, 2014: 160 163; Varol, 2017: 54):

Araç Takip Sistemi: Toplu taşıma araçlarına takılan mobil terminal üniteleri ile GPS uydularından konum bilgisi sağlanmakta ve GPRS aracılığıyla Araç Takip Merkezi ile iletişime geçilmektedir. Bu sistemin, uygunsuz kullanımın önlenmesi, araç ve personel güvenliğinin sağlanması, araçların ekonomik ömrünün uzatılması ve bakım giderlerinin azaltılması, otobüs hatları bilgilendirme sistemine ait mobil ve web uygulamalarına yönelik altyapı hizmetinin sağlanması gibi yararları bulunmaktadır. 
Otobüs Hatları Bilgilendirme Sistemi Mobil Uygulamaları(EGO Cep’te): Ankara Büyükşehir Belediyesi EGO Genel Müdürlüğü, akıllı telefonlarla uyumlu olarak geliştirdiği mobil uygulamalar ve internet üzerinden de hizmete sokulan bir uygulama ile otobüslerin nerede olduğunu, yaklaşık kaç dakika sonra durağa geleceğini, durak ve hat bilgilerini otobüs kullanıcılarına sunmaktadır.

Ankara Trafik Yoğunluğu Haritası: Bu uygulama anayol, bulvar, cadde ve sokakların anlık trafik yoğunluğunu izleyebilme olanağı sunmaktadır. Kullanıcılar 51 noktada canlı yayın yapan kameralara ulaşarak trafik durumunu canlı olarak izleyebilmekte ve yol çalışmalarını anlık takip edebilmektedir.

Trafik Kontrol Merkezi: Trafik yoğunluğunu, trafik kameralarını ve sinyalizasyon cihazlarının çalışmasını izlemek ve kontrol etmek üzere kurulmuş bir birimdir. Trafiği olumsuz etkileyecek durumlar harita üzerine işlenerek güncel bilgi paylaşımı yapılmaktadır.

Ankara Kart: Ekonomik ve pratik bir biçimde ulaşımın sağlanması için temassız akıllı kart uygulaması olarak geliştirilmiştir. Veriler GPRS aracılığıyla merkeze iletilmekte ve toplu taşıma alışkanlıkları tespit edilebilmektedir.

Akıllı Durak Sistemi: Otobüslerin durağa ne zaman geleceğini vatandaşa bildirmek için 120 merkezi noktada Durak Bilgilendirme Sistemi bulunmaktadır. Durakta bulunan ekranlardan duraktan geçen otobüs bilgileri ve anlık olarak geliş süreleri paylaşılmaktadır.

\section{Kocaeli Büyükşehir Belediyesi’nin Akıllı Ulaşım Sistemlerinin Analizi}

Türkiye'nin önemli sanayi kuruluşlarının yer aldığı Kocaeli, Marmara Bölgesi’nde Asya ve Avrupa'yı birbirine bağlayan önemli bir kavşak konumundadır. Ekonomik faaliyetlerin yoğunlaştığı bölgesel bir merkez olarak hızlı bir kentsel gelişime gösteren Kocaeli'nde hareketlilik oranı, gelişen sanayi ve hizmetlere bağlı olarak yolculuk talebi ve araç sahipliği her geçen gün artış göstermektedir (Akman ve Alkan, 2016: 56).

Karayolu ulaşımı, topografik yapı ve ülke karayolu ağının önemli parçası olan D-100 Karayolunun kent merkezinden geçmesi nedeniyle ulaşım türleri arasında öne çıkmıştır. Özellikle kent merkezinde ve ana koridorlarda önemli trafik sıkışıkları yaşanmaktadır. Konutlar ve merkez arasındaki erişimi kısıtlayan bu durum kent merkezindeki toplu taşıma planlaması ve trafik düzenlemelerinin yetersizliği nedeniyle de ciddi sorunlara yol açmaktadır (Akman ve Alkan, 2016: 56). Bu bağlamda sanayi etkinliklerinden kaynaklanabilen hava kirliliğine karayolu trafiğine bağlı olarak yaşanan kirlilik ve sorunların da eklenmesi kentiçi ulaşım sisteminin dünyada gelişen yeni yaklaşımlar çerçevesinde çevreye duyarlı bir biçimde yeniden düzenlenmesini gerekli kılmaktadır. Daha önce de belirtildiği üzere kentin yaşam kalitesinin ve erişilebilirlik olanaklarının artırılmasında önemli katkılar sağlayan akıllı ulaşım sistemlerinin Kocaeli'nde uygulanması bahsedilen sorunların çözümünde önemli bir role sahiptir.

Çalışma kapsamında Kocaeli Büyükşehir Belediyesi tarafindan gerçekleştirilen akıllı ulaşım uygulamalarının hangi aşamada olduğunu, akıllı ulaşım sistemlerinin akıllı kent politikalarını nasıl etkilediğini tespit etmek üzere uygulamaların yoğunlaşmış olduğu Toplu Taşıma Şube Müdürlüğü, Otobüs İşletmesi Müdürlüğü ve Akıllı Şehirler ve Kent Bilgi Sistemleri Müdürlüğü’nde mülakatlar gerçekleştirilmiştir. Çalışmada, görüşmeciler G1, G2 ve G3 olarak kodlanmıştır.

Türkiye'de diğer kentlerde olduğu gibi Kocaeli'nde de akıllı kent politikaları kapsamında yerel yönetimler tarafından gerçekleştirilen uygulamaların daha çok akıllı ulaşım bileşeninde somutlaştığ 1 görülmektedir. Kocaeli Büyükşehir Belediyesi'nde yapılan mülakatlar sonucu akıllı kent uygulamalarının farklı birimlerce dağınık bir biçimde yürütüldüğü tespit edilmiştir.

Akıllı kent alanına ilişkin uygulamaların daha bütüncül bir anlayışla yürütülmesi adına daha önce Kent Bilgi Sistemleri Müdürlüğü olarak görev yürüten birim 2019 y1lında Akıllı Şehirler ve Kent Bilgi Sistemleri Müdürlüğü olarak yenilenmiştir. $\mathrm{Bu}$ değişimin yaşanmasında daha önce de belirtildiği üzere 
son yıllarda akıllı kent alanına duyulan ilginin artması ve üst politika belgelerinde yerel yönetimlerin bu alanda yol haritalarını belirlemesi hususunda alınan kararların etkili olduğu düşünülmektedir (G3).

Akıllı Şehirler ve Kent Bilgi Sistemleri Müdürlüğü’nde yapılan görüşmede, henüz farklı birimlerce parçalı bir biçimde yürütülen uygulamalar hakkında bilgi toplama aşamasında olunduğu belirtilmiştir. Akıllı kent alanında yapılacak uygulamaların incelenerek ilgili birime aktarılması noktasında koordine edici bir rol üstlendikleri tespit edilmiştir (G3).

Mülakatlar ve faaliyet raporlarından derlenen bilgiler sonucunda Kocaeli’nde akıllı ulaşım sistemleri kapsamında gerçekleştirilen uygulamalar şu şekilde sıralanabilir:

- Ak1ll Sinyalizasyon Sistemleri ve Sinyalizasyon Kontrol Merkezi

- Kocaeli Büyükşehir Belediyesi Toplu Ulaşım Kontrol Merkezi

- Kentkart ve Temassiz Kart

- Değişken Mesaj Sistemi

- E-Komobil Uygulamas1

- Ak1ll Duraklar

- Ak1llı Direkler

- Kocaeli Akıllı Bisiklet Sistemi (KOBİS)

- Yeşil Dalga Uygulaması

\subsection{Akıllı Sinyalizasyon Sistemleri ve Sinyalizasyon Kontrol Merkezi}

Akıllı ulaşım sistemleri arasında kavşak içi zaman kaybının azaltılması amacıyla yaygın olarak kullanılan sinyalizasyon uygulamaları Kocaeli’nde 2008 yılında kullanılmaya başlanmıştır.

“Büyükş̧ehirlerin genelinde ortaya çıkan en önemli sorun ulaşımdır. Günümüzde bu sorunun çözümü için teknolojiden ve akıllı ulaşım sistemlerinden faydalanılması kaçınılmazdır... Kocaeli’nde 2008 yılında İSBAK ile birlikte bu süreç başlamıştır. Şu anda 200- 220 civarında sinyalize kavşak var. Geçiş öncelikli sistem, engelli geçişine uyumlu yaya butonları ve kavşakların olduğu yerlerde MOBESE'ler bulunmaktadır... 2009 yılında sinyalizasyon kontrol merkezi kurulmuştur” (G1).

2016 yılında yenilenen Sinyalizasyon Kontrol Merkezi kente ait kamera görüntülerinin canlı olarak izlenebilmesi, kavşak yaklaşım alanlarının takip edilebilmesi ve sinyalize kavşakların gerçek zamanlı olarak yönetilebilmesine olanak sağlayacak biçimde geliştirilmiştir. Sinyalizasyon kontrol merkezinin sahip olduğu özellikler şu şekilde sıralanabilir (Kocaeli Büyükşehir Belediyesi, 2018: 139);

- Gerçek zamanlı sinyalize kavşak yönetimi

- Sinyalize kavşak arıza takip sistemi

- Sinyalize kavşak bilgi sistemi

- Planlama ve koordinasyon

- Sinyalizasyon arıza çağrı

Akıllı sistem mantığı ile çalışan sinyalize kavşaklar, araçların bekleme sürelerinin ve zaman kaybının azaltılması, yol akışının gereksiz kesintisi önlenmesi için verimli bir biçimde kullanılabilmektedir. Araçların duruş-kalkış hareketlerinin ve dolayısıyla yakıt tüketimlerinin azaltılmasıyla çevreye verilen zararın da azalması bu sistemin kullanılması ile sağlanan diğer bir kazanımdır. Vatandaşlara hem zaman hem de ekonomik açıdan yarar sağlayan bu uygulama ile kentte güvenli bir trafik akışının sağlanması kolaylaşmaktadır (G1). 


\subsection{Kocaeli Büyükşehir Belediyesi Ulaşım Kontrol Merkezi}

Kocaeli Büyükşehir Belediyesi bünyesinde biri Gebze Hizmet Binası'nda diğeri İzmit'te olmak üzere iki adet ulaşım kontrol merkezi bulunmaktadır. Çalışma kapsamında mülakatların gerçekleştirildiği İzmit'te yer alan birimde gözlemde bulunulmuştur.

“(Ulaşım Kontrol Merkezi), toplu ulaşım sistemini tek bir merkezden yönetmek üzere tasarlandı. Teknolojiden yararlanarak araç içi kameralar ile sürekli denetim sağlıyoruz. Araçlar duraklarda ne kadar bekliyor, güzergahlar ihlal ediliyor mu anlık olarak izleyebiliyoruz...Toplu ulaşımda ve trafikte yaşanan sıkıntıların azaltılması açısından önemli rolü var” (G1).

Resim1: Kocaeli Büyükşsehir Belediyesi Ulaşım Kontrol Merkezi

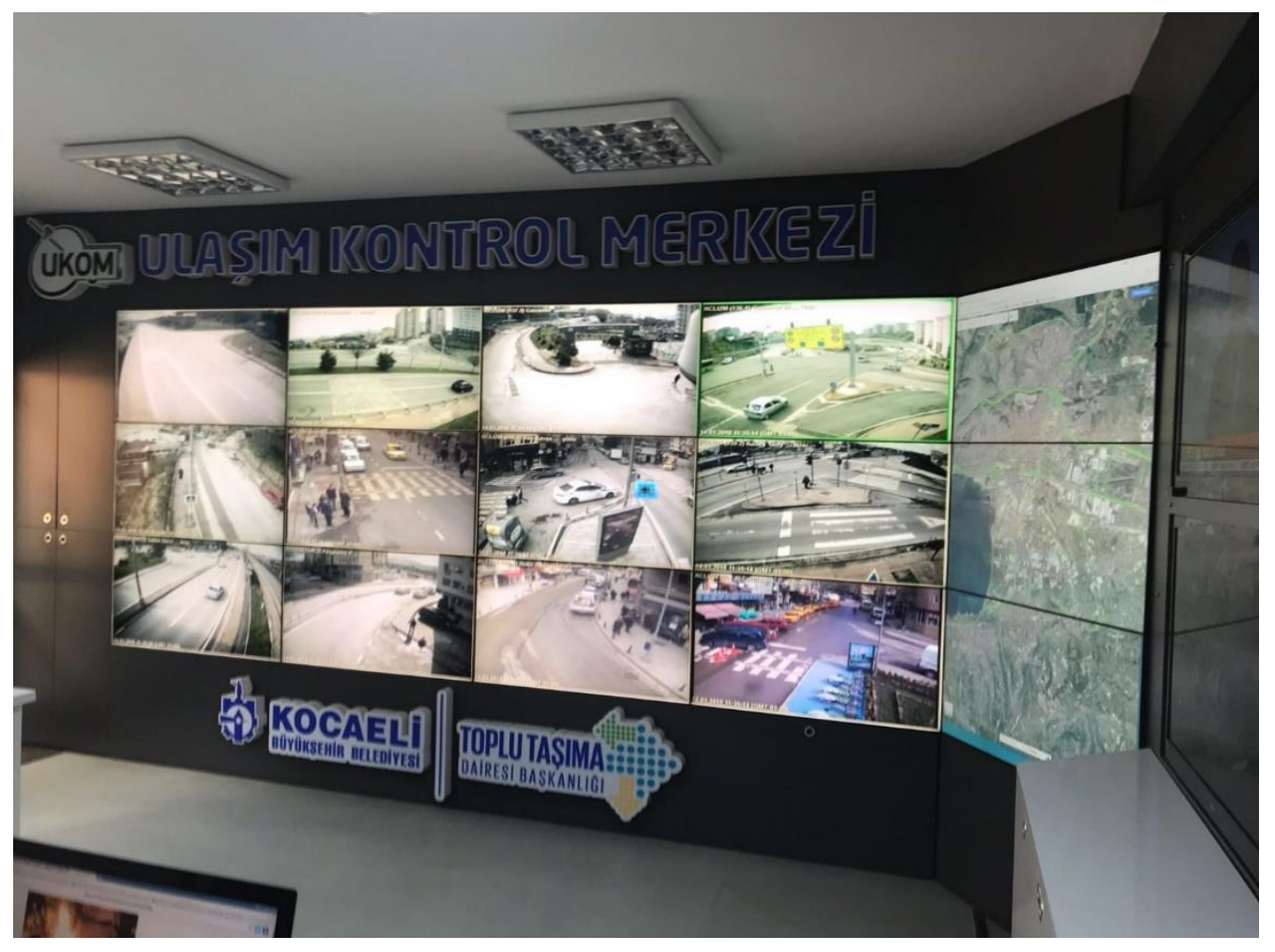

Toplu ulaşım kontrol merkezinin faaliyetleri; gözetim takibi, sefer takibi, durakta aşırı bekleme tarifi, aşırı hız kontrol takibi, tarife takibi, personel kontrol takibi, indirimli ve sivil kentkart işlemleri, çağrı merkezine ulaşan şikayetlere anlık müdahale olarak sıralanabilir (Kocaeli Büyükşehir Belediyesi, 2013: 300).

Kentteki toplu ulaşım faaliyetlerinde yaşanan aksaklıkların giderilmesi ve daha sağlıklı bir ulaşım yapısının tesis edilmesi amacına yönelik olarak kontrol merkezi, sorunları tespiti ve denetim noktasında önemli faydalar sağlamaktadır (G1). Yapılan görüşmelerde mevcut yapının geliştirilerek İstanbul örneğindeki trafik kontrol merkezine benzer bir sistemin oluşturulması adına çeşitli çalışmaların yürütüldüğü bilgisi elde edilmiştir.

\subsection{Kentkart ve Temassiz Kart}

Kocaeli'de 2006 yılında toplu taşımada kullanılmakta olan otomatik ücret toplama sistemi olan Kentkart uygulamasına geçilmiştir. 2016 yılından itibaren ise temassız özelliği taşıyan banka kartı, kredi kartı ve cep telefonlarının toplu taşımada ödeme işlemi için kullanabilmesi sağlanmıştır (kocaeli.bel.tr, 10.05.2019). 


\subsection{Değişken Mesaj Sistemi}

Değişken mesaj sistemi; olumsuz hava koşullarında, yoğun trafik, kaza ve yol çalışması gibi durumlarda sürücüleri yönlendirerek, zaman ve yakıt tasarrufu, güvenli bir trafik akışı ve ulaşım ağı kapasitesinin etkin kullanımı gibi önemli katkılar sağlayan bir uygulamadır (isbak.istanbul, 11.04.2018).

Kocaeli Büyükşehir Belediyesi yetkilileri ile yapılan görüşmelerde kentin çeşitli yerlerinde (Başiskele, Körfez, İzmit) toplamda 3 adet bulunan değişken mesaj sistemi panolarının aktif bir biçimde kullanılamadığı aktarılmıştır. Bu uygulamayla elde edilecek kazanımların sağlanması adına gerekli altyapı çalışmalarının yürütüldüğü bilgisine ulaşılmıştır $(\mathrm{G} 1)$.

\subsection{E-Komobil Uygulaması}

Kullanıcıların ulaşım planlarını güvenilir ve güncel bilgilerle gerçekleştirebilmeleri için gerekli tüm bilgilerin tek bir mobil uygulama altında toplanması amaçlanmıştır. Uygulamada bulunan akıllı durak ekranı ile kullanıcıların durakta bekleme sürelerini en aza indirebilmeleri için online olarak araçlardan alınan GPS verileri doğrultusunda duraklara yaklaşan araçlara ait hat, durak ve dakika bilgilerini sunmaktadır (e-komobil.com, 10.05.2019).

Uygulama ile "nasıl giderim” bölümünde Kocaeli ili sınırlarında listeden seçilen iki durak veya harita üzerinde işaretlenen çıkış ve varış noktaları arasında yapılacak olan yolculukla ilgili farklı gidiş seçenekleri sunulmaktadır. Kullanıcı bu seçenekler ile yolculuğunun kaç saat süreceğini, hangi hatları kullanacağını, hangi durakta binip hangi durakta ineceğini, yürüyerek yapacağı yolculuğunu ve diğer tüm bilgileri harita üzerinde ve adım adım görebilmektedir. Ayrıca trafik yoğunluğu haritası ve kapalı güzergahlarla ilgili adres ve tarih bilgileri uygulamayla sunulan diğer hizmetler arasındadır (kocaeligazetesi.com.tr, 10.05.2019).

\subsection{Akıllı Durak}

Otobüs duraklarına yerleştirilen dijital tabelalar aracılığıyla kullanıcılar belediye otobüsleri ve özel halk otobüslerinin nerede olduğunu takip edebilmektedir. Akıllı duraklarda yaygınlaştırılmaya çalışan bir diğer uygulama ise akıllı direklerdir. Güneş panelleriyle elektrik üreten akıllı direkler, üretilen elektriği depolayarak kullanıma sunmak üzere USB çıkışlarına göndermektedir. İnterneti olmayan ya da şarjı biten kullanıcıların gece ve güneşsiz günlerde de hizmetten yararlanmalarını sağlamaktadır (kocaeli.bel.tr, 10.05.2019).

\subsection{Kocaeli Akılı Bisiklet Sistemi (KOBİS)}

Kocaeli sınırları içerisinde kent içi ulaşımı kolaylaştırmak, toplu taşıma sistemlerini destekleyici nitelikte ara imkanlar oluşturmak, çevresel ve sürdürülebilir bir ulaşım aracının kullanımını teşvik etmek amacıyla ak1llı bisiklet kiralama sistemi oluşturulmuştur (kobis.com.tr, 10.05.2019).

Mülakatlar sonucu elde edilen bilgilere göre KOBİS'in önemli bir alternatif ulaşım imkanı oluşturduğu ve kullanım sayılarının her geçen gün arttığı tespit edilmiştir. Bisiklet paylaşım sisteminin uygulamaya geçmesi ve yaygınlaşmasıyla bireysel kullanıcıları da teşvik edici bir rol oynadığı düşünülmektedir (G2).

Tablo3: KOBİS istasyon, bisiklet ve üye sayıları

\begin{tabular}{|l|l|l|l|}
\hline Yıllar & $\begin{array}{l}\text { Akıllı Bisiklet } \\
\text { İstasyonu }\end{array}$ & $\begin{array}{l}\text { Akıllı bisiklet } \\
\text { Sayısı }\end{array}$ & $\begin{array}{l}\text { Akıllı Bisiklet } \\
\text { Toplam Üye Sayısı }\end{array}$ \\
\hline 2014 & 15 & 100 & - \\
\hline 2015 & 18 & 136 & 15.632 \\
\hline 2016 & 35 & 236 & 38.411 \\
\hline 2017 & 35 & 236 & 63.750 \\
\hline 2018 & 70 & 498 & 125.888 \\
\hline
\end{tabular}

Kaynak: Kocaeli Büyükşsehir Belediyesi 2014, 2015, 2016, 2017 ve 2018 yıllarına ait faaliyet raporlarından tablolaştırılmıştır. 


\subsection{Yeşil Dalga Uygulaması}

Seçilmiş olan güzergahlarda belirli bir hızda seyahat edildiğinde tüm trafik 1şıklarından yeşil ile geçiş yapmayı sağlayan bu sistemle zaman ve yakıt tasarrufu sağlanmakta, karbondioksit salınımı en aza indirgenmekte olup çevre duyarlılığı göz önünde bulundurulmaktadır.

Kocaeli'nde yedi ayrı bölgede toplam 28 adet kavşakta "Yeşil Dalga Sistemi" bulunmakta olup bu güzergâhta işletme hız1 ${ }^{2}$ dikkate alındığında 1şılklara takılmadan geçiş yapılabilmektedir (Kocaeli Büyükşehir Belediyesi, 2018: 138, imo.org.tr, 26.02.2020).

Akıllı ulaşım sistemlerinin etkin olarak kullanılması kentlerdeki yaşam kalitesinin yükselmesini de beraberinde getirmektedir. Nüfusu ve araç yoğunluğu hızla artan Kocaeli’nde akıllı ulaşım politikalarının kapsamlı bir biçimde uygulanması gerekliliği görüşmeciler tarafından da dile getirilmiştir. Daha önce de belirtildiği üzere akıllı ulaşım kapsamında çeşitli uygulamalar hayata geçirilmiştir ve yeni gelişen teknolojiler takip edilerek geliştirilmektedir.

Mevcut yol ağı kapasitesinin etkin olarak kullanılması, trafik, yol ve meteorolojik bilgilerin sürücülere anlık olarak iletilmesi, can ve mal kaybının en aza indirilmesi, zaman tasarrufunun sağlanması, kazaların azaltılarak ekonomik kayıpların önüne geçilmesi gibi hedeflerin gerçekleştirilmesine yönelik olarak bir trafik kontrol merkezi kurulma aşamasındadır. Akıllı durak sayılarının artırılması ve kent merkezinde yeni yapılan yatırımlardan biri olan tramvayın enerjisinin bir kısmının güneş enerjisinden sağlanması için girişimlerde bulunulmuştur. Öte yandan mobil uygulamalar, akıllı durak ve direkler, akıllı bisiklet paylaşım sistemi gibi uygulamaların halkın gündelik yaşamını kolaylaştırdığı ve olumlu geri dönüşler alındığını belirtmek gerekir.

Kocaeli'nde akıllı ulaşım sistemleri uygulamalarının geliştirilmesi, özel araç yerine toplu ulaşımın kullanılması, akıllı bisiklet paylaşım sistemi gibi alternatif ulaşım seçeneklerinin yaygınlaştırılması ve mevcut durumda sadece kent merkezinde başlatılmış olan tramvay gibi raylı sistemlerin artırılması hedeflenmektedir. Bu sayede kentteki ulaşım kaynaklı hava kirliliğinin azalması ve kentteki yaşam kalitesinin artması beklenen kazanımlar arasındadır. Akıllı ulaşım sistemleri teknolojik gelişmelerden yararlanarak daha hızlı ve ekonomik bir ulaşım yapısının oluşturulmasına ve hizmet maliyetlerinin düşmesine katkı sağlamaktadır. Ancak kuruluş maliyetlerinin yüksek olması ve uzman personel ihtiyacı belediyelerin karşılaştığı sorunlar arasında yer almaktadır.

\section{Sonuç}

Dünyada metropol alanların yönetiminin gittikçe daha karmaşık bir hal alması yeni yönetim tekniklerine olan ihtiyacı arttırmaktadır. Nüfus hareketleri ve nüfus yoğunluğunun ortaya çıkardığ çıkabilmek için bilgi ve iletişim teknolojileri ulusal ve yerel yönetim aktörlerine elverişli imkanlar sunmaktadır. Nitekim özellikle birçok gelişmiş ülkede kentlerin yönetiminde artan oranda bilgi ve iletişim teknolojilerinden yararlanılmaktadır. Akıllı kent politikaları birçok yerel yönetimin vizyon belgelerinde yerini almakla kalmayıp uygulamaya geçirilmiştir. Kentte yaşayanların yaşam kalitesini arttırmaya odaklanan akıllı kent politikalarında akıllı ulaşım sistemlerine işlerlik kazandırmak öncelikler arasında yer almaktadır.

Türkiye'de merkezi kurumlar, özel sektör ve yerel yönetimler akıllı ulaşım uygulamalarıyla ilgili çalışmalar yürütmektedir. Kentsel yaşamı etkileyen en önemli sorunlardan biri olması nedeniyle yerel yönetimler tarafından gerçekleştirilen akıllı kent uygulamaları ulaşım alanında yoğunlaşmaktadır.

Teknolojinin kentsel yaşamda etkin bir biçimde kullanılmasını, sorunların daha akılcı çözümlerle, pratik ve hızlı bir biçimde çözülmesini ve kent sakinlerinin yaşam kalitesinin artırılmasını mümkün kılan akıllı ulaşım uygulamalarının etkin bir biçimde hayata geçirilmesi Türkiye'de özellikle büyükşehirler için önem

\footnotetext{
2 İşletme hızı: Serbest akım koşullarında sürücülerin yaptıkları hızlardır.
} 
arz etmektedir. $\mathrm{Bu}$ amaçla daha net hedeflerin saptanması, üniversiteler ve araştırma kurumlarının bu konuyla ilgili çalışmalar yürütmesi ve belediyelere uygulamaların gerçekleşebilmesi için destek sağlanması gerekmektedir.

Çalışmada örnek olarak Kocaeli Büyükşehir Belediyesi’nin akıllı ulaşım sistemleri incelenmiştir. Bu incelemenin sonucunda Kocaeli'nde akıllı ulaşım anlayış ve uygulamalarının kurumsallaşma süreci yaşadığı söylenebilir. Türkiye'deki genel durumla örtüşür biçimde Kocaeli'nde akıllı ulaşımla ilgili uygulamalar parça parça gerçekleştirilmektedir. Yöneticilerle yapılan görüşmelerde özellikle çevreci bir ulaşım alternatifi olan bisiklet paylaşım sisteminin başarılı bir biçimde uygulandığ talepler doğrultusunda her geçen gün geliştirildiği görülmüştür. Toplu ulaşımla ilgili bir kontrol merkezi kurulması kentteki trafiğin daha güvenli bir biçimde gerçekleşmesine yardımcı olacaktır. Diğer yandan akıllı kavşak, akıllı durak ve değişken mesaj panolarının sayılarının artırılması gereği ve bu sistemleri entegre bir biçimde yönetecek bir üst kontrol merkezine olan ihtiyaç kendini göstermektedir. Nitekim yöneticilerle yapılan görüşmelerde İstanbul örneğindeki trafik kontrol merkezine benzer işlevlere sahip olacak bir birimin kurulma aşamasında olduğu belirtilmiştir.

\section{Kaynakça}

Akbaş, A. (2013). Türkiye'nin 2023 Akıllı Ulaşım Vizyonu ve Ulusal AUS Mimarisinin Geliştirilme Yöntemi Üzerine. Transist 2013 Bildiri Kitabı (271-276). Transist 6. Ulaşım Sempozyumu ve Fuarı 25-26 Aralık 2013 İstanbul Kongre Merkezi.

Akı1lı Ulaşım Sistemleri Derneği(AUSDER). (2017). Akıllı Ulaşım Otomasyonunda Yasal Çerçeve ve Düzenleyici Politikalar-AB ve Türkiye'de Durum (Rapor No.: 1).

Akman, G., Alkan, A. (2016). "İzmit kent içi ulaşımda alternatif toplu taşıma sistemlerinin aksiyomlarla tasarım yöntemi ile değerlendirilmesi”. Pamukkale Üniversitesi Mühendislik Bilimleri Dergisi, 22(1), 54-63.

Blanchet, M., Georges, O. G. (2009), Plan directeur des systèmes de transport intelligents (STI) de la Ville de Montréal Les systèmes de transport intelligents au service du Plan de transport de la Ville de http://conf.tacatc.ca/english/resourcecentre/readingroom/conference/conf2009/pdf/Blanchet.pdf Erişim Tarihi: (15.03.2018).

Çerçi, İ. (2015). Akı1lı Kentler bir ihtiyaç ve geleceğe dönük yaşam biçimidir. Bilişim Dergisi , 196-200.

Dameri, R.P. (2013). Searching for smart city definition: A comprehensive proposal. International Journal of Computers \& Technology, 11(5), 2544-2551.

Ercoşkun, Ö. Y., Karaaslan, Ş. (2009). Geleceğin Ekolojik ve Teknolojik Kentleri. Megaron , 4(1):27-34.

Eroğlu, İ. (2013). Akıllı Toplu Ulaşım Sistemleri ve Yolcu Hareketliliği. Transist 2013 Bildiri Kitabı (153-162). Transist 6. Ulaşım Sempozyumu ve Fuarı 25-26 Aralık 2013 İstanbul Kongre Merkezi.

Giffinger, R. , Fertner, C. , Kramar, H. , Kalasek, R., Pichler-Milanovic, N., Meijers , E. (2007) . Smart cities - ranking of European medium-sized cities. Centre of Regional Science, Vienna.

Hall, R. E. (2000). The Vision of a Smat City. Proceedings of the 2nd International Life Extension Technology Workshop. Paris. 
https://www.kocaeligazetesi.com.tr/haber/1303107/gunde-20-bin-kisi-e-komobil-kullaniyor, Erișim Tarihi: 10.05.2019.

https://www.isbak.istanbul/akilli-ulasim-cozumleri/trafik-bilgilendirme-sistemleri/degisken-mesajsistemi-dms/, Erişim Tarihi: 11.04.2018.

https://e-komobil.com/index.php, Erișim Tarihi: 10.05.2019.

http://www.imo.org.tr/resimler/dosya_ekler/076c0fddfd81194_ek.pdf, Erişim Tarihi: 26.02.2020.

https://www.kocaeli.bel.tr/tr/main/birimler/toplu-tasima-sube-mudurlugu/85/30253, Erişim Tarihi: 10.05.2019.

https://www.kocaeli.bel.tr/tr/main/news/haberler/3/ulasimda-temassiz-kart-donemi-basladi/28180, Erișim Tarihi: 10.05.2019.

http://ville.montreal.qc.ca/documents/Adi_Public/CE/CE_DA_ORDI_2014-03-

05_08h30_Systemes_de_transports_intelligents.pdf, Erişim Tarihi: 15.03.2018.

Journal officiel de l'Union européenne (2010), $\underline{\text { https://www.bison- }}$ fute.gouv.fr/IMG/pdf/D3_Directive_STI_100707.pdf, Erişim Tarihi: 16.03.2018.

Kanter, R. M., Litow, S. S. (2009). "Informed and Interconnected: A Manifesto for Smarter Cities. Harvard Business School Working Paper, No. 09-141.

Kesgin, İ., Aydemir, Y., Dolaner, R. R. (2014). Akıllı Şehirler- Ankara Akıllı Ulaşım Sistemleri. TBD (Türkiye Bilişim Derneği) 31. Ulusal Bilişim Kurultayı Bildiriler Kitabı (159-164). Ed. Selçuk Özdemir, İ. İlker Tabak. Ankara: Türkiye Bilişim Derneği.

Kocaeli Büyükşehir Belediyesi. (2014). Faaliyet Raporu, https://www.kocaeli.bel.tr/wmebfiles/userfiles/files/faaliyet-raporlari/2014-

FAAL\%C4\%B0YET\%20RAPORU.pdf

Kocaeli Büyükşehir Belediyesi. (2015). Faaliyet Raporu, https://www.kocaeli.bel.tr/webfiles/userfiles/files/faaliyet-raporlari/2015_Y1_Faaliyet_Raporu.pdf Kocaeli Büyükşehir $\quad$ Belediyesi. (2016). Faaliyet https://www.kocaeli.bel.tr/webfiles/userfiles/files/faaliyet-raporlari/2016_Y1_Faaliyet_Raporu.pdf
Kocaeli
Büyükşehir
Belediyesi.
(2017).
Faaliyet
Raporu,

https://www.kocaeli.bel.tr/webfiles/userfiles/files/faaliyetraporlari/2017\%20Faaliyet\%20Raporu.pdf

Kocaeli Büyükşehir Belediyesi. (2018). Faaliyet Raporu, https://www.kocaeli.bel.tr/webfiles/userfiles/files/faaliyet-raporlari/2018_Faaliyet_Raporu.pdf

MTES/MCT (Ministère de la Transition écologique et solidaire - Ministère chargé des Transports) (2017), Les systèmes de TRANSPORT INTELLIGENTS L'EXPERTISE FRANÇAISE, https://www.idrrim.com/ressources/documents/9/5218-14085_Transport-intelligent_Web_pla.pdf $(15 / 03 / 2018)$. 
Partridge, H. (2004). Developing a Human Perspective to the Digital Divide in the Smart City. Proceedings of the Biennial Conference of Australian Library and Information Assocation . Oueensland, Australia: http://eprints.qut.edu.au/1299/1/partridge.h.2.paper.pdf.

Sınmaz, S. (2013). Yeni Gelişen Planlama Yaklaşımları Çerçevesinde Akıllı Yerleşme Kavramı ve Temel İlkeleri. Megaron , 8(2).

Şengül, R. (2017). Akıllı Kent Politikalarının Gelişimi, İBANESS, Kırklareli, 23-24 Eylül 2017, s.451456.

T.C. Çevre ve Şehircilik Bakanlığı. (2019). 2020-2023 Ulusal Akıllı Şehirler Stratejisi ve Eylem Planı.

T.C. Kalkınma Bakanlığı Bilgi Toplumu Dairesi Başkanlığı. (2014). Bilgi Toplumu Stratejisi ve Eylem Planı 2015-2018.

T.C. Kalkınma Bakanlığı. (2013). Onuncu Kalkınma Planı 2014-2018.

T.C. Cumhurbaşkanlığı Strateji ve Bütçe Başkanlığı. (2019). On Birinci Kalkınma Planı 2019-2023.

T.C. Kalkınma Bakanlığı. (2017). Sürdürülebilir Kalkınma Hedefleri Kapsamında Türkiye’nin Mevcut Durum Analizi Raporu.

T.C. Ulaştırma, Denizcilik ve Haberleşme Bakanlığı. (2014). Ulusal Akıllı Ulaşım Sistemleri Strateji Belgesi (2014-2023) ve Eki Eylem Plan1 (2016-2016).

Tektaş, M., Korkmaz, K., Erdal, H. (2016). Akıllı Ulaşım Sistemlerinin Geleceği(Ekonomik ve Çevresel Faydalar1). Balkan Sosyal Bilimler Dergisi , 561-577.

Türkiye Bilişim Vakfı. (2016). Türkiye Akıllı Şehirler Değerlendirme Raporu. http://www.novusens.com/turkiye-akilli-sehirler-hazirlik-degerlendirme-raporu/ Erişim Tarihi: (11.10.2017).

United Nations Population Funds. http://www.unfpa.org/ Erişim Tarihi (15.11.2016).

Varol, Ç. ( 2017). Sürdürülebilir Gelişmede Akıllı Kent Yaklaşımı: Ankara'daki Belediyelerin Uygulamaları. Çă̆daş Yerel Yönetimler ,26(1): 43-58.

Yaman, H. T. (2014). Akıllı Ulaşım Sistemleri Tanımı ve Kapsamı. Akıllı Ulaşım ve Güvelik Sistemleri, 54.

Yardım, M. S., Akyıldız, G. (2005). Akıllı Ulaştırma Sistemleri ve Türkiye'deki Uygulamalar. 6. Ulaştırma Kongresi, (405-414). Türkiye.

XSIGHTS (2016), "Akıllı Kentler Masabaşı Araştırması-Kamu Teknoloji Platformu", https://docplayer.biz.tr/33725407-Haziran-akilli-kentler-masabasi-arastirmasi.html (Erişim Tarihi: 07.09.2017). 